\title{
THE INFLUENCE OF THE FREE DISPENSARIES UPON MEDICAL EDUCATION IN BRITAIN
}

\author{
by
}

\author{
SIR ZACHARY COPE
}

THE PART played by the Free Dispensaries in the evolution of medical education in Britain has not yet been adequately appreciated. This may initially have been due to the campaign of vilification of dispensaries carried on by Thomas Wakley in the early years of the Lancet, for such campaigns often leave a lasting impression on readers who are not informed of the other side of the question. The rapid spread of the number and popularity of the dispensaries proved their value to the community, while the Report of the Select Committee of the House of Commons on Medical Education (1834) provided unequivocal evidence of their educational importance. They filled a gap in the teaching of clinical medicine.

The teaching of clinical medicine in Britain was later in beginning than the teaching of surgery. Anatomy and surgery were taught by several surgeons in the early years of the eighteenth century and William Cheselden's Anatomy of the Humane Body, based upon his lectures and practical demonstrations, was published in 1713 and was destined to undergo thirteen editions before the close of the century. Then, soon after the separation of the Barbers from the Surgeons in 1745, William Hunter opened his School of Anatomy that ultimately settled in Great Windmill Street, and soon other private anatomical-surgical schools followed. During this time the only regular teaching of medicine was by Dr. George Fordyce (1736-1802), ${ }^{1}$ who for thirty years onward from 1764 lectured on medicine, chemistry and materia medica at his house in Essex Street, Strand. At this time there was no other regular instruction given in medicine in London. On page 89 of that delightful book Mr. Guy's Hospital, ${ }^{2}$ it is stated that in 1768 'it was then agreed that students should be allowed to attend the surgical practice of both hospitals although no corresponding arrangement was made as to medical practice for the good reason that at the time teaching in medicine did not exist'.

Opportunities for medical teaching were however soon to be provided in the Aldersgate Street Dispensary founded, largely owing to the enthusiasm of John Coakley Lettsom, ${ }^{3}$ in 1771. From the very first, Lettsom had it in his mind to use the clinical material at the Dispensary for teaching purposes. In his Medical Memoirs, published in $\mathbf{1 7 7 4}$ he analysed the various kinds of disease afflicting patients seen at the Dispensary or visited at their own homes during the previous year, and gave clinical descriptions of many of them. The total number of cases was 1650 , of whom 512 had been seen at their homes. Though there is no evidence that Lettsom actually taught at the Dispensary it is clear that he contemplated doing so, for in his pamphlet on The Improvement of Medicine in London (1775) he discussed the use of the General Dispensary as a school of physic, and made the practical suggestion that 'young 


\section{Zachary Cope}

gentlemen of genius might pay ten pounds per annum for the privilege of attending the practice of the dispensary and hearing a lecture each day'. He was, however, cautious enough to add that 'this plan may not be fully executed for some time'. The late Johnston Abraham was, however, of opinion that two of the manuscript volumes now preserved in the Library of the Royal Society of Medicine under the title 'Lettsom-Materia Medica' were probably intended as an outline of lectures that he had intended to deliver to students at the Dispensary, but there is no evidence that they were ever delivered. There is little doubt that Lettsom's suggestions influenced others who took advantage of the opportunities offered to teach at dispensaries.

At the Westminster Dispensary in Gerrard Street Mr. Edward Ford was in 1776 granted permission to take a clinical surgical pupil so that teaching was soon permitted there.4 The late Mr. W. E. Tanner was of the opinion that students of the Great Windmill Street School learnt their medicine at the Westminster Dispensary ${ }^{5}$ but $I$ have been unable to confirm this from inspection of the Dispensary records. In $1776^{\circ}$ in Edinburgh Dr. Andrew Duncan founded the Public or Old Town Dispensary where it is more than likely that he made use of the clinics for the purpose of teaching his students, for, though he was extra-collegiate lecturer on medicine, he was not in charge of beds at the Infirmary.

The first and one of the best examples of regular clinical teaching in medicine was that systematically carried out by Robert Willan and later by Thomas Bateman at the Public Dispensary, Carey Street, near Lincoln's Inn, from 1783 onwards for thirty years. Willan set a pattern both of clinical research and teaching which indelibly impressed itself upon British medicine. Willan has well been called the founder of British dermatology, and it would scarcely be going too far to say that he was the first to give regular clinical teaching in medicine. Let us consider what he did for clinical medicine.

Robert Willan? (1757-1812) was the son of a Quaker doctor in practice at Sedburgh, Yorkshire. He graduated at Edinburgh University in 1780, attended some lectures in London, probably at Great Windmill Street School, practised in Darlington for a short time and then came to London where he was appointed physician to the newlyopened Dispensary in Carey Street. He also became physician to the London Fever Hospital, and obtained the licentiateship of the Royal College of Physicians in 1785. His pioneer work in dermatology was done at the Dispensary, but he also made accurate observations upon the prevalence of various diseases at different seasons of the year. He published his observations in a work entitled Reports on the Diseases of London. His main teaching was done at the Dispensary. The extent and the fame of his reputation can best be judged by the remarks made in the biography of Willan in Munk's Roll of the Royal College of Physicians (vol. II, p. 351): 'The Public Dispensary, in the course of Dr. Willan's tenure of office there, became a favourite school with young physicians for instruction in the practical part of their profession. His practice there was very numerously attended, and many (it was said more than forty) physicians who subsequently attained to a foremost place in reputation and business in London and elsewhere, were among his pupils.'

After twenty years of devoted work at the Carey Street Dispensary Willan resigned 


\section{Influence of Free Dispensaries on Medical Education in Britain}

his office and was made consulting physician to the charity by the governors, who also presented him with a handsome piece of silver as a mark of their appreciation of his work. Willan was one of the most original observers of his time, and his educational work at Carey Street Dispensary needs to be emphasized, for by his example and precept he taught the leading young physicians of an important period of medicine. Not least among his pupils was Thomas Bateman, whose ability Willan recognized so that he got Bateman appointed physician both to the London Fever Hospital and the Carey Street Dispensary, where he succeeded Willan, and continued his clinical teaching and dermatological researches.

Thomas Bateman, ${ }^{8}$ whose genius developed late and withered early, was born at Whitby in 1778, being the son of a surgeon in that town. After three years' apprenticeship in Whitby he came to London where he attended classes at the Great Windmill Street School and was a pupil at St. George's Hospital. He then went to Edinburgh where he graduated in medicine in 1801. Coming back to London he studied under Willan at the Carey Street Dispensary, and later succeeded him. Bateman absorbed Willan's teaching, followed his methods, developed his master's views on dermatology and in 1813 published $A$ Practical Synopsis of Cutaneous Diseases, which proved an immediate and lasting success. He continued Willan's Reports on London Diseases and maintained and increased the reputation for clinical teaching that the Carey Street Dispensary had gained under Willan. According to Munk, among the physicians who attended Bateman's clinic were Drs. P. M. Latham, W. F. Chambers, Richard Bright and Thomas Addison, ${ }^{9}$ all of whom became famous clinicians. Both Bright and Addison served for a time as assistant to Bateman at the Dispensary, Bright for only one year but Addison continued to serve the charity for seven years. Both of them continued to subscribe to the Dispensary after they had severed their connection with it. This was the golden period of the Carey Street Dispensary. The Dispensary continued to be active for more than another hundred years, but on account of building changes in the neighbourhood the Dispensary changed its site to Bishop's Court and was known as the Bishop's Court Dispensary. Two other changes of site occurred before it became the Drury Lane Dispensary, which name it retained until the coming of the National Health Service.

\section{TEACHING AT THE ALDERSGATE STREET DISPENSARY}

We have already referred to Lettsom's plan for teaching at the Aldersgate Street Dispensary, though we have no evidence that he started classes there. He may, of course, have allowed pupils to attend with him at the clinics held there but no records of this are available. We know, however, that Dr. Henry Clutterbuck ${ }^{10}$ taught there for many years from 1809 onwards. Clutterbuck was a Cornishman born in 1770 at Marazion; he served an apprenticeship in Truro, then studied at Guy's and St. Thomas's Hospitals and, after becoming a member of the Corporation of Surgeons, practised in the City and began the publication of the Medical and Chirurgical Review. Desiring to practise as a physician he graduated in medicine at Glasgow in 1804, became a licentiate of the Royal College of Physicians of London in the same year, and started in practice in St. Paul's churchyard. He was elected to the staff of the General Dispensary, Aldersgate Street, in 1807 and began to lecture on medicine 


\section{Zachary Cope}

and materia medica. Munk states that 'His lectures are said to have been like his writings, plain, forcible and unadorned; full of practical facts and with an entire absence of speculation. He delivered three courses on each subject in the year and commanded a numerous class. His receipts from this source alone are said in one year to have exceeded one thousand pounds'.

Clutterbuck's lectures made the Aldersgate General Dispensary an educational centre. It was not surprising that later, in 1825, a medical school was started in Aldersgate Street, though the Dispensary and the School were separate institutions. In fact, Clutterbuck and his colleagues at the Dispensary resigned from that institution in 1833 owing to a quarrel with the governing body. His lectures at the School continued for some years after this.

\section{MEDICAL EDUCATION AT THE DISPENSARIES FROM 1815-1858}

The educational influence of the dispensaries from 1770 to 1815 was limited to London, but from 1815, the date of the passing of the Apothecaries' Act, their influence extended throughout the country while at the same time it was increased in the Metropolis. Few people realize to what an extent the clinical facilities of the dispensaries were used during that important period.

The passing of the Apothecaries' Act in face of the opposition of the physicians, the surgeons and the chemists was a remarkable achievement largely due to the persistent and skilful sagacity of George Man Burrows. That Act put the control of medical education for those who intended to enter general practice into the hands of the Society of Apothecaries. What to many seemed a foolish and even desperate venture actually turned out to be a resounding success, for the Society of Apothecaries quickly laid down a useful curriculum, established good standards, and encouraged, and sometimes compelled the setting up of provincial medical schools and made use of both hospitals and dispensaries for the teaching of clinical medicine. One of the conditions which a candidate had to fulfil before he could enter for the qualifying examination in medicine at Apothecaries' Hall was to attend either a hospital, infirmary, or dispensary for a period of at least six months. This necessary clinical practice was later extended to nine months in 1824, and in 1828 it was laid down that 'no certificate of attendance on any public hospital or dispensary shall be received unless the testimonial is signed by all the physicians belonging to the establishment'. Three months later a further regulation stated that the candidate must not do his medical practice at a hospital or dispensary until after he had completed his first course of lectures on the principles and practice of medicine. It is quite clear that the court of examiners carried out their duties conscientiously, and took every opportunity to improve the curriculum, for in September 1830 they insisted that the attendance on the clinical practice at a dispensary should be for at least fifteen months 'at a dispensary connected with some medical school recognized by the court'.

In order to show how careful the Society of Apothecaries was in guarding the necessary qualifications as regards the clinical teaching in dispensaries, it is useful to study the letter sent out by the Court of Examiners to all dispensaries in London on 7 February 1833. It ran as follows: 
his caves anreng the wane he has ffeerates an -

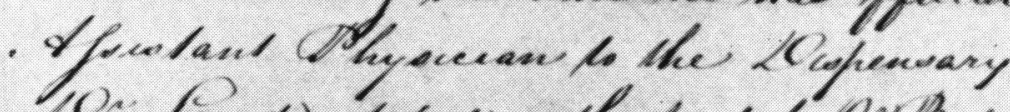

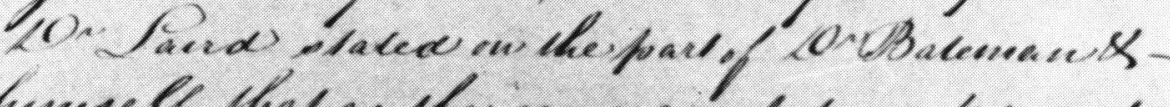

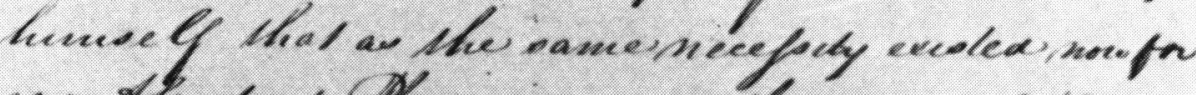

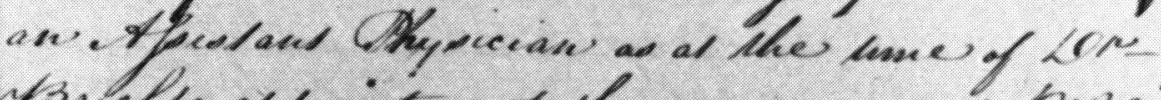

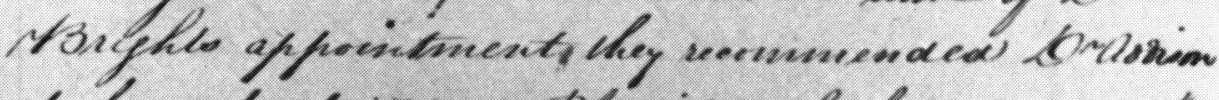

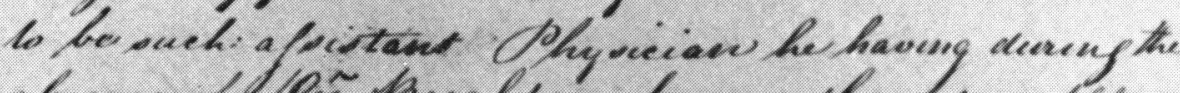

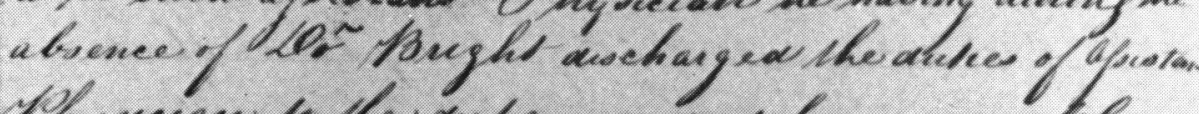

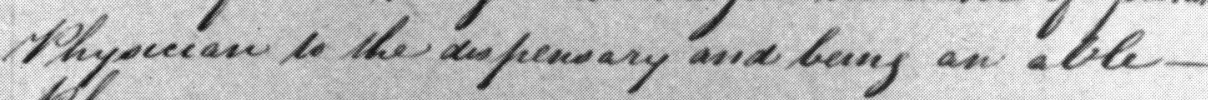
Physecase. -

bceodved

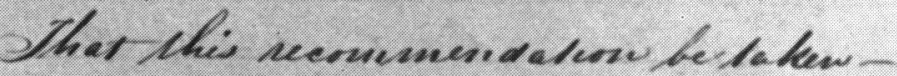

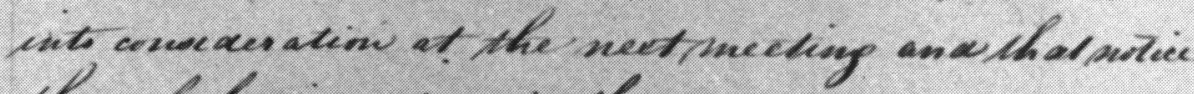

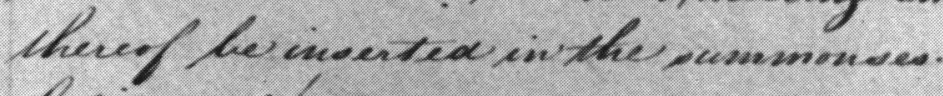

1 Coxioumed

- Ho che towpensary

Shavent Lo Bobth

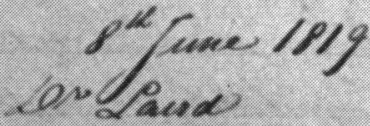

$$
\text { Lor Dateman }
$$$$
\text { - lovactumo }
$$

The brim

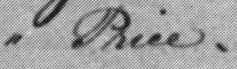

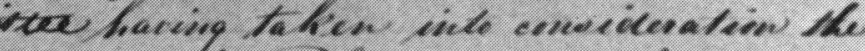

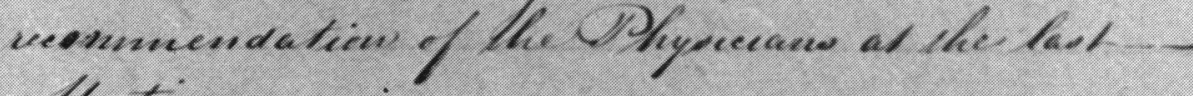
- Ulating

pertoed

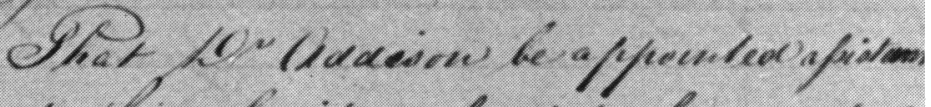

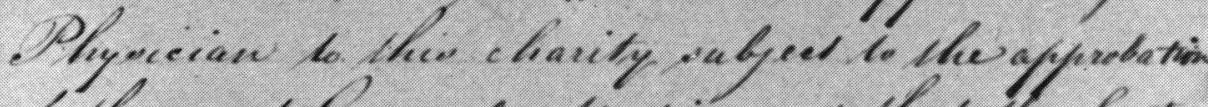

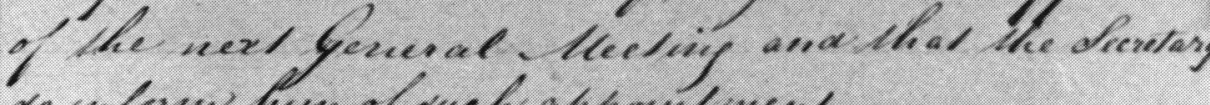

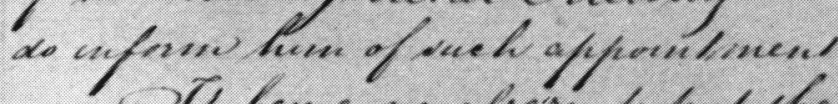

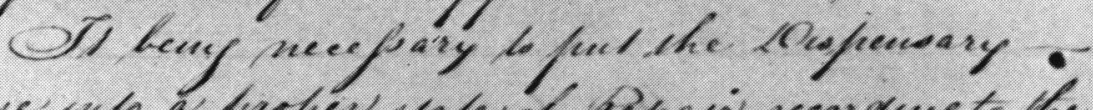

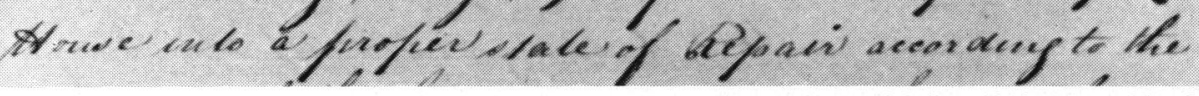

By courtesy of the Royal College of Physicians of London A page from the Carey Street Dispensary Minute Book recording the appointment of Thomas Addison as Assistant Physician in succession to Richard Bright, for whom he had often deputised. 


\section{Influence of Free Dispensaries on Medical Education in Britain}

To the Physicians of D Dispensary

\section{Gentlemen,}

I am instructed by the Court of Examiners to call your attention to the notice relative to Dispensaries which were published in their Regulations of the Court for September 1830 and in August 1832, and to remind you that the time for acting upon them is now arrived. The Court are ready to receive applications for the recognition of dispensaries from the physicians attached to those institutions respectively; and with the view of saving unnecessary trouble to the medical officers the Court have further instructed me to state that they will recognize as schools of practical medicine such Dispensaries only as shall give satisfactory evidence of the following points-viz That the Dispensary is situated in some city or town in which there is a medical school recognized by the Court.

That the rules for the government of the Dispensary permit the attendance of students, and that the physicians afford them opportunity of acquiring practical knowledge of medicine. That the Dispensary (if within the limits of jurisdiction of the Royal College of Physicians of London) is under the care of at least two physicians, each of whom is a Fellow, Candidate or Licentiate of the Royal College, and if beyond these limits, that it is under the care of at least two physicians who, if not so qualified, are graduated doctors of Medicine of a British University of four years standing.

And that the apothecary of the Dispensary is legally qualified either by having been in practice prior to or on the 1st of August 1815, or by having received a certificate of qualification from the Court of Examiners.

I have the honor to be, Gentlemen your obedient servant

John Watson, Secretary

N.B. Every certificate of attendance is to be signed by all the Physicians connected with the Dispensary attended by the student; and the Court especially request that no certificate may be signed unless the pupil has been uniformly regular in his attendance.

That these regulations of the Court were no mere formality may be judged by the fact that when St. Mary's Hospital, Paddington, was opened in 1851, and although it had been officially recognized by the Royal College of Surgeons of England, it was for a time refused recognition by the Court of Examiners of the Society of Apothecaries because there was no legally licensed apothecary resident in the building nor any medical school attached to it. Only after these defects were remedied was recognition duly granted.

\section{THE AMOUNT OF CLINICAL INSTRUCTION AT THE DISPENSARIES}

It is fortunately possible to give accurate details of the practical effect of these regulations, for in 1834, on the initiative of Thomas Wakley (Member of Parliament for Finsbury and Editor of the Lancet), a Select Committee of the House of Commons was set up to ascertain the main facts about medical education in Britain, and from the information given in their report the following data has been obtained (see Report of the Select Committee of the House of Commons on Medical Education, 1834, Appendix to Part II, p. 18).

In the three years 1831,1832 , and 1833 , the total number of candidates for the examination in medicine at Apothecaries' Hall amounted to 1,336 of whom 1,171 passed. Of this number there were 222 candidates who had gained their clinical experience in London or Provincial Dispensaries and of these as many as 193 successfully passed the examination. (There were in addition 40 candidates who had obtained their experience at the Dispensary recently established in Gower Street in connection with the new London University.)

In London the Dispensaries which gave clinical instruction for the examination 


\section{Zachary Cope}

were fifteen in number, as follows:

\begin{tabular}{|c|c|c|}
\hline $\begin{array}{l}\text { Islington } \\
\text { Aldersgate Street } \\
\text { The Surrey } \\
\text { St. George's and St. James } \\
\text { The Western }\end{array}$ & $\begin{array}{l}\text { The South London } \\
\text { The Central } \\
\text { Tower Hamlets } \\
\text { Finsbury } \\
\text { The City }\end{array}$ & $\begin{array}{l}\text { Middlesex } \\
\text { Farringdon } \\
\text { Westminster General } \\
\text { Carey Street } \\
\text { Bloomsbury }\end{array}$ \\
\hline
\end{tabular}

In the Provinces dispensaries in the following places were utilized for giving instruction to candidates:

$\begin{array}{lll}\text { York } & \text { Kidderminster } & \text { Exeter } \\ \text { Wakefield } & \text { Chorlton } & \text { Birmingham } \\ \text { Salford and Pendleton } & \text { Wigan } & \text { Falmouth } \\ \text { Clifton } & \text { Liverpool North } & \text { Bristol } \\ \text { Ardwick and Ancoats } & \text { Leeds } & \end{array}$

These figures were taken from years when the Aldersgate Street Dispensary was very active so that it is not surprising that thirty-five candidates came from that dispensary, but it was scarcely to be expected that as many as seventy-five candidates were signed up from the Surrey Dispensary, for that was not far from Guy's Hospital where Bright and Addison were at the height of their reputation as clinical teachers. During these years 157 students from Guy's and 178 from St. Thomas's went up for the final examination in medicine and it is possible that the crowds of students at those hospitals induced some men to attend the less crowded Dispensary clinic.

It will have been noted that the Court of Examiners of the Society of Apothecaries insisted that no recognition would be granted to any dispensary that was not related to a recognized medical school. When the Apothecaries' Act was passed there were no medical schools (other than Oxford and Cambridge) outside London, but by 1834 there were no less than fourteen provincial medical schools that must have been established as a direct result of the Court's regulation. From 1834 to 1858, when the Act that established the General Medical Council was passed, the dispensaries maintained their educational function with diminishing importance. After 1858 they lost that educational function almost completely in England and Wales, but in Scotland it was retained until recent times.

Few details of the methods of teaching adopted at the dispensaries are available. We know that for a time Michael Ryan lectured on medicine at the Westminster Dispensary, Gerrard Street and concerning him J. F. Clarke wrote in his book of reminiscences as follows:"11 'Ryan was one of the physicians of the Western Dispensary, in Charles Street, Westminster, and most of his students at the Gerrard Street school were also his pupils at that institution. At this time the Apothecaries Company received the certificate of fifteen months' attendance at a recognised dispensary as evidence that the candidate for their licence had passed through a sufficient course of Practical Medicine.'

Clarke states that Ryan's class contained about 150 pupils but it must be assumed that only a certain number could be permitted to attend the Dispensary any one day.

Although Thomas Wakley was an unsparing critic of dispensaries it is only fair to say that he included information about the educational facilities they afforded in the columns of his journal the Lancet. For example, in the period we have been con- 


\section{Influence of Free Dispensaries on Medical Education in Britain}

sidering the following note appeared in the Lancet $(1833-34, i, 3$.$) : 'There are also$ numerous dispensaries in the Metropolis offering opportunities for attendance on medical practice, and certificates of attendance on many of which are received at Apothecaries' Hall as proofs of a qualification to be examined for the licence of the Company.'

From this advertisement we are able to ascertain the charges made for instruction at the Dispensaries, for the notice continues: 'The terms for attendance on these vary but little. The fees at St. George's and St. James's Dispensary, King Street, Golden Square, may be quoted as a specimen. The charges for attendance on the medical establishment is for fifteen months $£ 66 \mathrm{~s}$. $0 \mathrm{~d}$., perpetual $£ 88 \mathrm{~s}$. $0 \mathrm{~d}$. Surgical practice, one year $£ 22 \mathrm{~s}$. $0 \mathrm{~d}$., perpetual $£ 55 \mathrm{~s}$. $0 \mathrm{~d}$.' In the same year as that in which the above notice appeared there was also an editorial note that ran as follows-it affords us the greatest satisfaction to be enabled to state that the humbug dispensary system is on the wane!'

The educational value of the dispensary was well shown at York where there was also a school of medicine functioning from 1834-1860. The Society of Apothecaries and the Royal College of Surgeons of England recognized both the York Dispensary and the York County Hospital. Dr. Margaret Barnet has kindly sent me the following information concerning the York Medical School and Dispensary.

Amongst the medical students who attended the Dispensary were at least three who achieved fame further afield. The first was Sir Jonathan Hutchinson, the famous surgeon, who studied at York from 1846 to 1850 . The second was destined to be the colleague of Hutchinson at the London Hospital-Hughlings Jackson, the neurologist. After taking his M.R.C.S. and L.S.A. Jackson returned to York and became house-surgeon to the York Dispensary until 1859. During that period he became a member of the York Medical Society and addressed the Society on several occasions. One of his lectures was, significantly on 'Four cases of Paralysis'.

A third distinguished alumnus of York Medical School was Daniel Hack Tuke, the mental specialist, who was a student in York from 1847 to 1850 and became physician to the York Dispensary in 1855. Dr. Thomas Laycock was for a time resident physician at the York County Hospital and in 1842 was appointed physician to the York Dispensary.

DISPENSARIES AS A STEPPING-STONE FOR PHYSICIANS

From an early date the dispensaries, especially those in London, were useful stepping-stones for those physicians who intended to become consultants. The experience gained as physicians to a dispensary qualified them for the service of a hospital.

In the provinces physicians who wished to practise in London found dispensaries useful places at which to gain experience and a reputation, even if they failed to obtain a post in a teaching hospital. Thus it was that Robert Willan gained his remarkable experience at the newly-opened Carey Street Dispensary from 1783 onwards. In the case of Peter Mark Roget, ${ }^{12}$ who gave up the important post of physician to the Manchester Infirmary in order to try to establish himself in London, he actually founded a dispensary in a part where one was needed-in North London-and from 1810 onwards he faithfully served this dispensary until 1828; he never obtained a post on the staff of a London Hospital.

As early as 1784 two physicians attached to dispensaries competed for the post of physician to the London Hospital. In his History of the London Hospital Dr. Clark- 


\section{Zachary Cope}

Kennedy relates that Dr. John Cooke, who was physician to the General Dispensary, Aldersgate Street, was successful in gaining the post against Dr. John Whitehead who was physician to the London Dispensary, Spitalfields.

\section{EDUCATIONAL FUNCTION OF THE DISPENSARIES IN SCOTLAND}

In Scotland the Dispensaries continued their educational function in those cities which had universities. Dispensary work became part of the normal curriculum of the medical student. In Edinburgh the Royal Public Dispensary, the New Town Dispensary and the Livingstone Dispensary all admitted students for clinical work. Recently the students have worked chiefly at the Livingstone Dispensary. In Glasgow the students worked in the General Public Dispensary or in Anderson's Dispensary. A detailed account of the methods adopted is to be found in The Medical Institutions of Glasgow (1888) by Dr. James Christie:

The Dispensary is open every lawful day at 1 p.m. and at 1.30 p.m. the medical officer is in attendance for the purpose of receiving and entering in a book the names and addresses of patients who require to be visited at their own homes. Thereafter $a$ list of the names and addresses of the cases, along with the names of the students in whose districts the patients reside, is made out and delivered to the students who are in attendance. The senior students have the home cases allotted to them, and they, in conjunction as far as possible with junior students, visit the cases. After a home case has been visited the student in charge, before the next dispensary visit, enters in a book opposite the name and address of the patient, the nature of the illness and the treatment recommended. Each student keeps a record of his cases in a pocket register provided for the purpose. In case of doubt, difficulty or danger the student consults the medical officer, and no prescription recommended by a student is dispensed unless it bears the initials of this officer. In addition, the dispensary visits the pensioners on the outdoor fund for the relief of incurables for Glasgow and the West of Scotland. These number about 150 and are attended by the students under the direction of the superintendent of the outdoor visiting department, each patient being visited on an average three times a year.

At the time that the above account was written the Anderson Dispensary was seeing over twelve thousand new cases each year, so that a mine of clinical experience was open to the students.

In Aberdeen and Dundee also the medical students had similar experience of home visiting, but since the Dispensaries were closed in 1948 arrangements have been made for the students to spend a definite period with an experienced doctor in general practice.

1. Dictionary of National Biography.

\section{REFERENCES}

2. Cameron, H. C., Mr. Guy's Hospital, London, Longmans, 1954, p. 89.

3. Abraham, James Johnston, Lettsom, his Life, Times, Friends and Descendants, London, Heinemann, 1933, p. 109.

4. Minutes of Westminster Dispensary (Royal College of Physicians Library).

5. Trans. med. Soc. Lond., 1947-49, 65, 232.

6. Dictionary of National Biography (Andrew Duncan, Sr.).

7. MUNK, W., Roll of the Royal College of Physicians of London, Vol. II, p. 350.

8. Ibid., Vol. III, p. 19.

9. Minutelbook of Carey Street Dispensary (Royal College of Physicians Library).

10. Dictionary of National Biography.

11. Clarke, J. F., Autobiographical Recollections of the Medical Profession, London, Churchill, 1874, pp. 133-34.

12. Dictionary of National Biography. 